This item was submitted to Loughborough's Research Repository by the author.

Items in Figshare are protected by copyright, with all rights reserved, unless otherwise indicated.

\title{
The implementation of a user-centred design approach by student industrial designers when designing for elderly and disabled people
}

PLEASE CITE THE PUBLISHED VERSION

http://dx.doi.org/10.2752/146069200789393571

\section{PUBLISHER}

Bloomsbury Journals (formerly Berg Journals)

VERSION

NA (Not Applicable or Unknown)

\section{PUBLISHER STATEMENT}

This work is made available according to the conditions of the Creative Commons Attribution-NonCommercialNoDerivatives 4.0 International (CC BY-NC-ND 4.0) licence. Full details of this licence are available at: https://creativecommons.org/licenses/by-nc-nd/4.0/

\section{LICENCE}

CC BY-NC-ND 4.0

\section{REPOSITORY RECORD}

Torrens, George E.. 2019. "The Implementation of a User-centred Design Approach by Student Industrial Designers When Designing for Elderly and Disabled People”. figshare. https://hdl.handle.net/2134/15753. 


\title{
Understanding the Product User: The Implementation of a User-Centre Design Approach by Student Industrial Designers when Designing for Elderly and Disabled People.
}

George Torrens

Loughborough University

\begin{abstract}
This paper describes the introduction of a new module to an undergraduate degree programme for Industrial Designers in the Department of Design and Technology, Loughborough University. The implementation of the module and its subsequent outcomes will be related to the changing professional needs of graduating industrial designers. The aim of the module is to enable students to practice the use of data collection techniques that provide evidence for their design decision making. It is also to emphasise the industrial designer's role in the development of the desirability of a product within a given social group. The objectives of the module are to: raise the awareness of industrial design students to the demographic shift towards older consumers and the needs of disabled people; introduce them to more rigorous methods of user assessment; gain an empathy with users outside their personal experience; and, provide students with an opportunity to apply their skills and knowledge in the field of user assessment. A research task enabled students to achieve the set objectives in collaboration with local community groups and individual elderly and disabled volunteers. The issues raised within this paper are also of relevance to practising industrial designers who wish to work in the field of Rehabilitation Technology/Assistive Technology (RT/AT) product development or enhance their knowledge of user-centred design. The paper provides the International industrial
\end{abstract}


design community with an introduction to the support infrastructure in the United Kingdom for the social groups involved in this work.

\section{Introduction}

The professional needs of industrial designers are changing. Computer Aided Industrial Design, new methods of production and materials technology are all accepted as changes to be assimilated and applied to the task of product development by design practitioners. Whilst these aspects of professional skills, knowledge and values are developed and updated within industrial design courses, issues such as the interpretation of user needs and aspirations have developed little. A new module, Design for Ageing and Disability, was introduced in the Department of Design and Technology in 1997/98 to redress the balance of skills and values taught. It is taught in year three of the undergraduate programme and complements the existing skills and knowledge taught on the two main programmes: Industrial Design and Technology and Industrial Design and Technology with Education. The module took a user-centred approach and takes data collection methods and techniques used in ergonomics and social sciences. Techniques such as questionnaire, interview and observation are widely known, and often used by practising designers but, to the authors knowledge, are not taught as a separate subject to student industrial designers on an undergraduate degree course.

The following case study will document the introduction of sixty-one undergraduate industrial designers to these formalised working practices over the last two years. Reasoning behind the development of the new module will be explained and evidence shown of the need for change in design education. Details of the methods and techniques taught, and outcomes of their practice by undergraduates, will be of interest to practising industrial designers who are expanding their expertise in to markets outside of their current knowledge. For the profession of industrial design to develop, undergraduates and practitioners require a more in-depth understanding of 
methods and techniques used to obtain focused user information. Besides providing evidence for a more quantifiable justification of design decision-making these techniques and methods offer designers a greater empathy with the people for whom they are designing.

\section{Design for Ageing and Disability}

Why do designers need more training in obtaining accurate information from a user or user group? A product design specification that accurately defines the user's needs may be considered an essential stage in the successful development of a product. The development of a robust product specification is dependent upon accurate information about the lifestyle, needs and aspirations of the target user or buyer as well as the functional constraints of manufacture (Torrens, 1997).

The demography of the United Kingdom population is changing. It has been reported that the United Kingdom population is moving towards a larger percentage of older people. It has been estimated that $50 \%$ of the population will be over 60 years old by the year 2003 (Design Age, 1996). Around 10\% of the UK population are registered as disabled (Sandhu and Wood, 1990). Most graduating industrial designers are young, healthy and often male and so have little experience of the needs or aspirations of what is a large percentage of the United Kingdom population.

Two terms often used in conjunction with products for elderly and disabled people are Rehabilitation Technology and Assistive Technology. Rehabilitation Technology (RT) products are those associated with the recovery of a patient to a more acceptable level of independence, such products include crutches and specialist exercise and activity equipment. Assistive Technology (AT) helps to maintain the independence of an individual within the community. Wheelchairs, tap-turners, environmental controllers and speech synthesis devices are AT products. Industrial Designers are most likely to be 
involved in the development of AT products. These products may also be considered to be convenience products.

It may be asked why older and disabled consumer groups have not been targeted by commercial organisations? Many disabled and elderly people rely on Government benefits such as invalidity, or mobility allowances and state pensions. For some product markets, such as tap and jar openers, the consumer has little to spend on these specialist items. If RT/AT products such as, hoists and environmental control devices are bought by the State, the emphasis on functionality and low cost provide small margins of profit for the producer; hence reducing funds to develop new products or technologies (Maynard 1995, Young and Sandhu 1995). State provided products compound the difficulties faced in providing a desirable and usable product because the professional adviser, often an Occupational Therapist, is looking for different attributes from the product specification, mainly functionality. Carers and family members also influence the purchasing decision-making. The number of viewpoints to be satisfied compounds the difficulties faced by a designer in acquiring appropriate information.

For some years final year students within the Department had undertaken projects in which they design products for elderly and or disabled people. Staff with appropriate knowledge supported students through tutorials and one-off seminars, but the increasing numbers undertaking such projects suggested a more specialised input should be offered. An important part of student learning was seen to be their direct contact with users. There were other aspects influencing the development of a new module. From research and development work undertaken by staff in the field of rehabilitation and assistive technology (RT/AT) products, it had already been identified that graduating designers required methods to better understand the needs and aspirations the user. The users perception of AT products and their methods of purchasing products are outside the personal experience of most undergraduate students. 


\section{Volunteer subjects}

For any researcher, finding suitable subject groups, that are large enough for a given study, is critical to the success of answering the questions posed. The following description highlights many sources of users for trials by industrial design practitioners or design educators. Many of the groups mentioned are local to Loughborough University. The charitable organisations involved, such as the Stroke Association, Arthritis Care, Age Concern and Age Forums, had been contacted each time at a Regional and National level during the previous summer before the start of the new academic year.

The use of local contacts sourced from National information centres had been found to be the most cost effective way for students to gain access to their target user. This has been found to be an effective way for the author, as a practising designer, to access users during the development of new products for the Assistive Technology market (Torrens and Kay 1995 Torrens et al, 1996). Practitioners should be aware that involving a charitable group in user trials within product development will incur costs for subject participation and travel expenses, hence the need to recruit groups locally.

To enable students to have a sample group with whom to work during the module, information outlining the module was circulated in the Loughborough and in surrounding areas of the Borough of Charnwood detailing what would be expected of volunteers. The local Government Social Services and Health Authority have a comprehensive and well-developed community support structure and information network, Charnwood Information Network (CHAIN) based around a day centre, John Storer House. There are such networks in each of the Regional Health Authorities in the United Kingdom and may be seen as cost-effective mechanism to obtain a sample user group. They are usually found in most local telephone directories under Charities or local Government. In the first year of running the module twenty subjects were 
identified as willing to help the students in the module in the first running of the module, with thirty volunteers for the second. During the first running of the module around six charitable or local Government organisations were involved. Once contacts had been established with local groups, it was easier to obtain a larger sample from one or two groups to be involved with the module in 1998/99.

It had been found that many local charitable support groups did not have the specific range of impairments required for the study. The criterion used to select suitable groups was based upon physical impairments. Most AT products cater for a person's resulting physical rather than mental disability or handicap. It is outside the ability of most industrial designers to assess the needs or aspirations of those with cognitive disorders that have no physical impairments or provide products to overcome those cognitive impairments. A design practitioner planning user assessments should expect to review many local support groups before finding groups and a sample number that suits their needs. However, once in contacted these groups have been shown to provide an effective pool of volunteers.

Portland College and the Loughborough Branch of the University of the Third Age were the two organisations involved with students undertaking the module in 1998/99. Portland College is a residential or day release college offering a range of courses to more severely disabled teenagers and young adults. There are similar centres around the UK. The University of the Third Age is a charitable support organisation that promotes the needs of more elderly members of the community and offers a range of social activities with branches nation-wide. These two groups offered a quite different range of volunteers. One provided young volunteers with a range of disabilities such as cerebral palsy, the other with volunteers who were apparently fit and healthy, but who had minor impairments such as hearing loss, poor eyesight or limited muscle strength or joint mobility. 
The two groups offer an example of the wide range of physical impairments and very different aspirations for products within society in the United Kingdom. The choice of user groups to be involved in any trials should be undertaken after reviewing available literature that most organisations of these types produce, often free or for a small fee.

\section{Implementation of the module}

The module 'Design for Ageing and Disability' ran for eleven weeks between late September and early December 1997, with feedback on assignment outcomes given in early 1998. It then ran again the next academic year, 1998/99. Thirty-one students took the module in 1997, thirty in 1998, with the module entailing 80 hours of student study.

The module was designed to give students:

- a knowledge of the demographics of elderly and disabled people in the UK and Europe;

- an appreciation of viewpoint of those are involved with the purchase of RT/AT products, including Government social services and manufacturers;

- a contextual framework within which to produce 'user mapping'.

- provide a number of formal methods through which to obtain information from consumers;

The module enabled students to:

- practice accessing RT/AT information from specialist sources;

- develop interpersonal skills.

The module focused on the practice of extracting lifestyle and physical ability information from members of the local community. It also provided design methodologies appropriate to the design and development of a successful RT/AT product. This related to past experience of staff in the field of RT/AT product 
development (Burkitt, Torrens, et al 1995, Torrens 1995, Torrens and O'Hare 1998). These methods included:

- standardisation of components used in a product range;

- modularity of component to expand consumer options within a product range;

- identifying additional consumer markets satisfied by the specialist product, expanding the production numbers;

- modification of existing products and product liability;

- designing 'mainstream' products to be easier to use (Usability), enabling use by a larger group of the population, including disabled and elderly people (Design for All);

- functional quality matrix; and,

- introducing user-centred factors to value engineering.

Sources of funding to assist in product development were also discussed.

The first three weeks involved three sessions of three one-hour lectures together with seminars and tutorials. Students were required to read specified sections of the module textbook, Userfit (HUSAT 1995), before attending the lectures and seminars. Userfit is a bibliography of terms, references, guidelines, recommendations and assessment tools. It is a reference guide for the development of products, specifically, RT/AT products. Arrangements were made for all students to receive individual copies of Userfit.

Staff and a post-graduate student with experience or qualifications in RT/AT product research and development, Occupational Therapy, or Ergonomics presented the lectures. A similar format was followed in year two of the module.

The lectures involved taking the students through three main categories of the Userfit textbook:

1. those parties who would directly use the product or system or be influenced by it;

2. the characteristics of these individuals or groups; and, 
3. the particular requirements that these individuals will have.

The seminars included exercises where the students in simulated user assessments used the following tools:

- Direct observation;

- expert opinion;

- questionnaires;

- interviews;

- group discussions;

- empathic modelling.

In both years the students practised observation and interview techniques as well as questionnaire construction. Each technique was taught and practised through one-hour seminars. In each seminar students were asked to obtain information about a given user.

Year Three students were considered competent in user mapping, brainstorming and had already received a lecture on task analysis in their second year of their course programme. Using the tool formats given in Userfit, students were asked to provide answers to given case studies. The case study results were then discussed in the seminar allowing students to reflect on the use of the techniques in their forthcoming assignments. 


\section{Direct observation, interview and empathic modelling}

Two students were asked to wear equipment that mimicked certain medical conditions. One student wore safety spectacles that were covered in opaque tape with only a small hole through which to see. This mimicked a condition called myopia or tunnel vision. This condition is usually associated with diabetes and old age. Another volunteer student was asked to wear hockey goalkeeper equipment. This mimicked the limitation of movement, loss of muscle strength and increases bulk associated with old age. The limitation of movement is also associated with rheumatoid and osteoarthritis.

Volunteer students were asked to complete a pre-determined course and tasks observed by the rest of the student's group (Figure 1 and Figure 2). Once completed the volunteer student discussed their experience with the rest of the group. This enabled the individual to gain more empathy with people with certain forms of disability, and the group to practice their interview and observation technique.

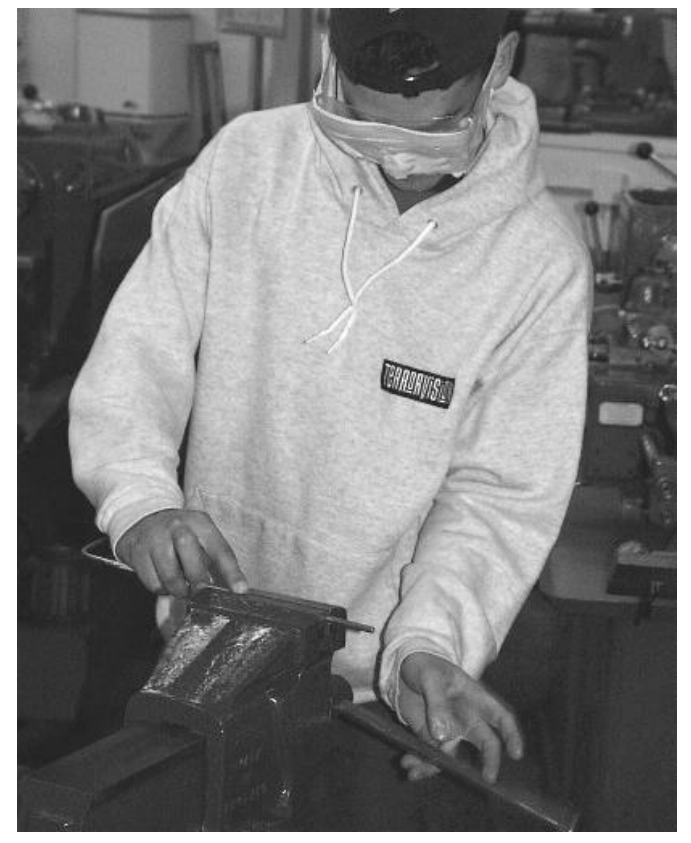

Figure 1. Shows a student subject attempting to complete a task wearing reduced vision glasses representing tunnel vision. 


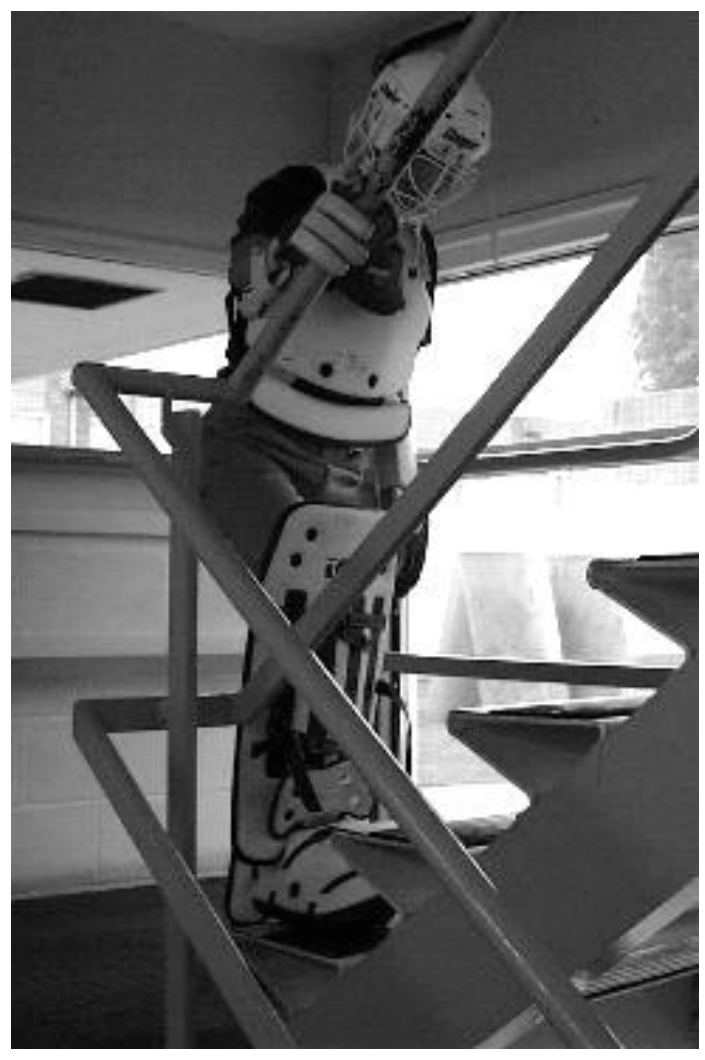

Figure 2 Shows a volunteer student walking up stairs whilst wearing hockey goal keeping equipment simulating the movement limitation and limited muscle strength associated with forms of arthritis and old age.

\section{Interviews}

In the case of interviewing the student groups were divided into groups of five and one member of each group asked to play the role of a given individual with a form of disability. The profiles of each user were produced by the students themselves using information they had gathered from completing assignment one. They were also asked to draw an illustration of the person to be played by one of their group. The volunteer from each group then moved to the next group and was interviewed by that group. Following the exercise, staff and students discussed issues raised in trying to apply market research methods to produce user profiles. The issues included interpersonal skills and the use of open-ended questions focusing onto more in-depth questions 


\section{Assignment one}

In the first week students were given handouts detailing the module schedule, assignment requirements and assessment structure. Assignment One was to be started immediately. This assignment was designed to complement the students growing understanding of the issues relating to RT/AT product research and development. It was also to familiarise the students with appropriate literature and electronic resources in the RT/AT field.

Students were also asked to choose a topic from a list of different groups of disability or impairment. The list included:

- Visual impairment,(or, people who are blind, or partially sighted).

- Hearing impairment, (or, those who are deaf due to illness, accident or injury).

- Neuro-muscular impairment, (or, people with motor neurone disease, multiple sclerosis, cerebral palsy or spinal injury).

- Musculo-skeletal impairment, such as people with forms of arthritis.

- Ageing, (or, a combination of other impairments including weak limbs and frailty).

- Stroke, (or, people recovering from or living with the consequences of having different levels of severity of hemiplegia).

Students were asked to choose an activity of daily living (commonly abbreviated to 'ADL' in clinical practice), such as shaving, cleaning, mobility or shopping. The chosen daily living activity was used to identify specific requirements to be considered when buying or designing a product to fulfill the specified needs. The list of activities was based upon guidelines developed by Occupational Therapists (Turner, Foster and Johnson, 1996).

Each student was required to produce a short report (500-1,000 words) outlining, from references, a definition of the medical conditions within the chosen group, details of specific functional requirements for the group, and generic products available to them. 
The term generic was used to define a type of product such as an attendant type wheelchair, rather than a specific manufacturers make or model. A substantial bibliography of contacts for further information and references was expected. Resources, such as information about Charities, product information guides, manufacturer's catalogue, academic journal references and conference proceedings had been put in place for this purpose within the Department and University library.

The students were aware their report would, if appropriate, be added to a information network called Usability-net, hosted on one of the Loughborough University Internet servers. The outcome of the work done by the students may be seen on the Usabilitynet website (http://www.info.lboro.ac.uk/info/usabilitynet/adl.html).

\section{Assignment Two}

This assignment provided $80 \%$ of the overall module grade. Through the use of scenarios students reviewed the inter-personal skills required as described earlier. Problems that might occur, such as inappropriate terminology used by the students, consideration of the volunteer as an individual, etiquette and the avoidance of irritation or confrontation with the subject were discussed. Students were asked to reflect on and propose solutions to given student-subject situations. In the first year of running the module students were made aware that they might need to take identification with them or arrange a password with volunteers who felt particularly vulnerable. Students were also tutored in listening impartially without being pro-active in the conversation. Students were advised to watch for signs of fatigue and not to continue beyond thirty minutes in any one meeting with their subject.

The format of Assignment Two followed by the students in 1997/98 was a series of meetings with their volunteers. The meetings were: 
- An introduction of subject and student and identification of the subject's needs through their initial comments on the specific activity, using a semi-structured interview;

- a longer interview involving task analysis of a specific part of a daily living activity;

- a review of the findings of the student with the subject.

In 1998/99 the students followed a slightly different format:

- Half of the thirty students undertook a detailed one-to-one observation of a student volunteer at Portland College over a period of one morning, followed by a semistructured interview over lunch;

- the other half of the students each prepared a questionnaire that was sent a member of the U3A, followed by a semi-structured interview one week later, based on the answers given in the questionnaire.

It was noticed that in the first year of the module running students did not take up the opportunity to work with more severely disabled children and adults in the first year of the module. On questioning the students did not feel capable of handling the emotional trauma of interviewing people so different from themselves. This was addressed in the second running of the module. Students were able to view a video of the disabled volunteers from Portland College, impressing on them the need to focus on the volunteer as a person and the questions to be answered rather than the volunteer's outward appearance.

In the first year of the module being taught students arranged to visit the volunteers in their homes. Each volunteer had been given the name of the student or students who would visit them as further security against an unwanted caller or visitor. The students used the same topic group such as musculo-skeletal or visual impairment, but were free to choose another daily living activity. The only constraint was that no member of the topic group could have the same activity. Because there were more students than subjects, two students visited the subject. Each student was to obtain information for 
his or her specific activity of daily living subject. In the second year of the module being taught, specific times for student and volunteer meetings were set for a single venue, Portland College for one half of the group, John Storer House for the other. Arranging for a group of volunteer users to meet student researchers, on a one-to-one basis, in a convenient venue was found to be a more effective use of time and resources. The neutral venue is of benefit for focused data collection and management of the task. However, more detailed lifestyle information may be obtained through documenting the user's domestic environment.

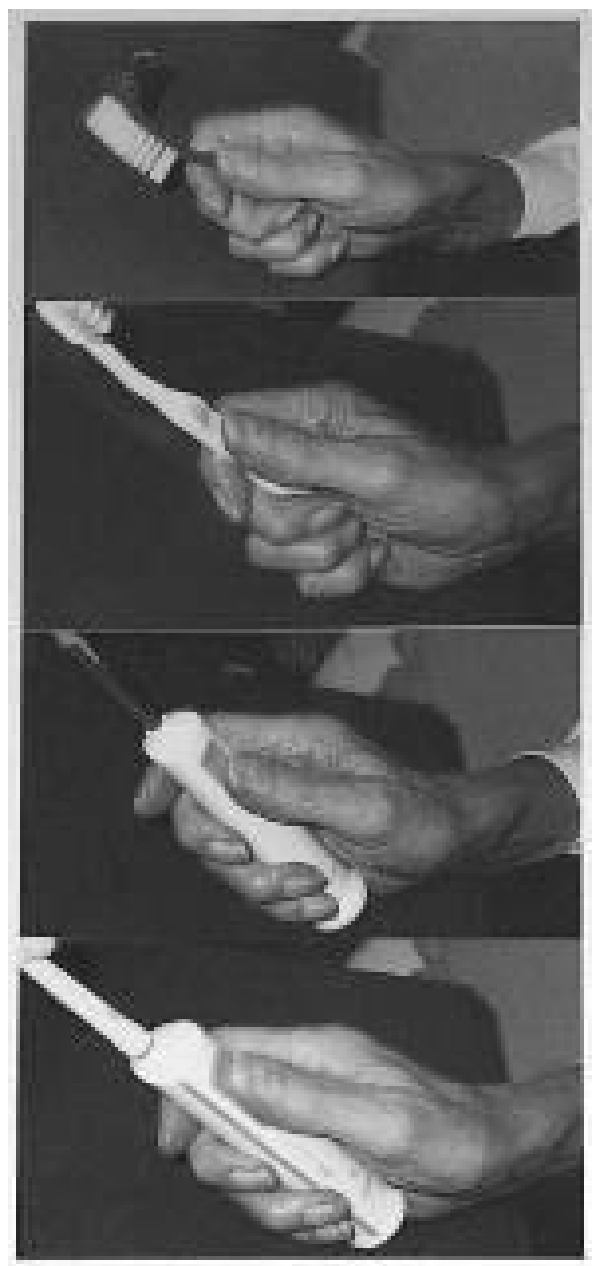

Figure 3. Shows a subject, who has a form of arthritis, being asked to use and comment on a range of proprietary dental hygiene products. 
In both years, following the collection of data and processing of results, students were asked to produce a report (2,000-2,500 words not including the introduction or bibliography). They were also asked to produce one or two boards that were to be used in their final presentation. The presentation was to staff, the student group and invited guests. The guests included the subjects interviewed, experts who had given students advice and representatives from charitable groups. The presentation boards were an opportunity for the students to put forward concept ideas for modifications to existing or completely new products. Presenting their design solutions back to their intended audience focused the student's attention on their presentation technique, visual and verbal. It also gave the opportunity for the students to obtain more feedback from the subjects, the target market consumers, and to reflect upon the accuracy of their findings and proposed solutions.

The report, presentations and presentation boards were graded, with the students given a combination of feedback sheets, comment written on their reports and a group feedback tutorial. In both years the students who attended feedback tutorials also completed University format module feedback sheets.

\section{Assessment outcomes}

During student tutorials in the first year of the module running the full range of interview techniques discussed in the lecture series had been used. Some students interviewed individuals, two or three students had initial meetings with a group of volunteers in a focus group format. The range of activities of daily living review methods included user trials and field trial product comparisons, not covered in the lecture series. Guidance had been available to the students through tutorials and the Userfit textbook.

Tutorials during the module had highlighted that five or six of the subjects interviewed stated "I haven't got any problems." Faced with such a strong viewpoint the students in 
many cases did not feel able to progress further with the interview. It was suggested to students that they get the subject being interviewed to explain how they go about the activity of interest, the students returned to their subjects. The outcome was that as the subjects were explaining how they performed the daily living activity of interest the student was able to note the alternative postures and 'tricks' used by the subject. Students were informed in more detail during lectures and seminars during the second year of the module being taught on how to get their subjects to provide useful information prior to the students undertaking interviews.

The late matching of students and subjects did affect the format and nature of the interviews and the way the results were documented. The original activity of daily living to be studied by some students had to be changed due to a limited availability of subjects. This issue affected around eight students. A number of students were proactive in finding volunteers and went to local branch meetings themselves, for example to arthritis care branch meetings. However, what they found was that most of those attending such meetings did not have any form of diagnosed arthritis. Other students contacted family members who they knew to have arthritis and interviewed them. In year two this was not highlighted as a problem, due to the well-defined user groups involved.

In 1997/98, four of the twenty volunteers attended the student presentations, with two representatives of local charity organisations and two human factor's experts who advised students. In the second year of the module running twenty-five of the thirty volunteers attended, plus carers and professional clinicians. Those in attendance in both years were very positive about the presentations during feedback to staff and students.

In 1997/98, the event was highlighted in the local community through a newspaper article and an interview with two of the students on a regional radio station. In the 
same academic year an exhibition of the students work was staged in a local community centre. In 1998/99 the work was on display in Portland College. Both exhibitions have been seen to strengthen links between the community and highlight the work undertaken by student industrial designers.

\section{Assignment submissions}

The presentations and reports of the 31 students reflected the application of their understanding of the module requirements and of the area of study. The students had the most difficulty in structuring their reports. The details of writing the report were left until the later tutorial sessions to avoid information overload of the students in the early part of the module. The students already had in their possession a University supplied 'students guide', a resource which outlined how to write reports. They had also received a lecture on how to write reports as part of another module. In 1998/99 the improved quality of the reports seemed reflect the more detailed guidelines given and supplementary tutorial support.

The information obtained by the majority of the students was of a good quality and a useful resource for researchers in the RT/AT field. The task analysis undertaken by

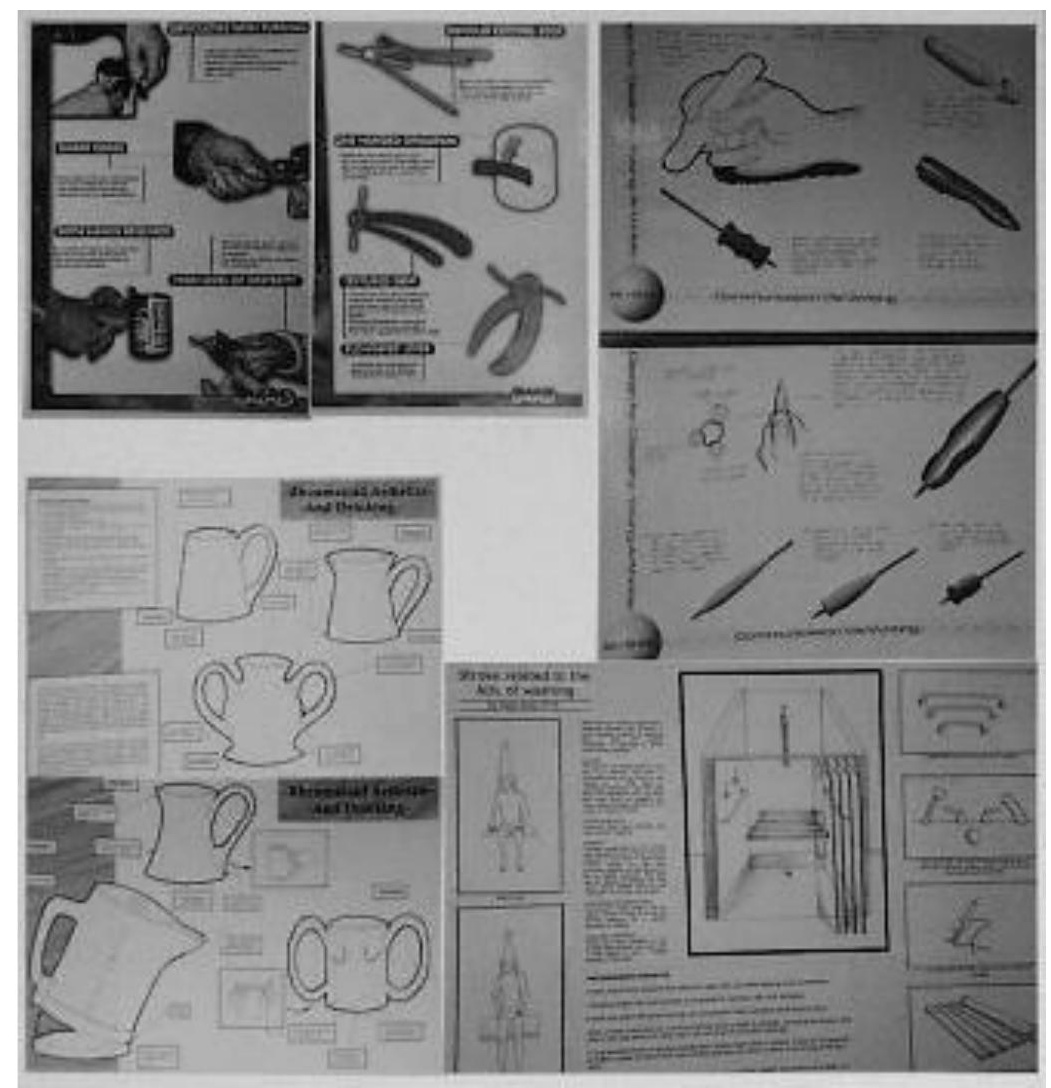


students provided a number of interesting points in each group of impairments studied. The study of their target users helped students produce a range of innovative quality design concepts. (See Figure 4) In 1997/98 some students were advised to discuss their ideas with a local manufacturer. The manufacturer concerned had taken two design solutions into development based on students work in previous years (Torrens, 1996).

Figure 4 Shows a range of images from presentation boards shown to the volunteer subjects and experts involved in Assignment Two in the academic year 1997/98

In 1998/99 a number of students used the information gained through their contact with different users to produce prototype solutions to needs not highlighted in the module. The design for an easy reaching device was based on the problems of reaching for every items whilst seated (See Figure 5). The problems with reaching items were highlighted whilst the student concerned was talking to people who have difficulty in getting out of chairs. Another student (See Figure 6) also took the design of a powered secateur through to a prototype stage. The problems involved within gardening, and specifically pruning, were highlighted during discussions with users from Portland College whilst the student was investigating an easy to use spade. Both students applied a user-centred approach to their major project designs, involving older users groups, related support groups, such as the Repetitive Strain injury support group Nottingham, and clinicians. The two prototypes are currently being reviewed by commercial companies. The interest from manufacturers, users and professionals involved with disabled and elderly people suggests the information students collected about the needs of the volunteers was accurate and the concept solutions they produced were robust in specification.

The submission results in this module over the two years seemed to reflect the quality of grades achieved by the same students in other modules. The highest graded students in this module showed initiative in finding, and obtaining, information from subjects 
within the short time scales given. Through their concept solutions the same students showed a good understanding of the issues to be reconciled within a given design solution.

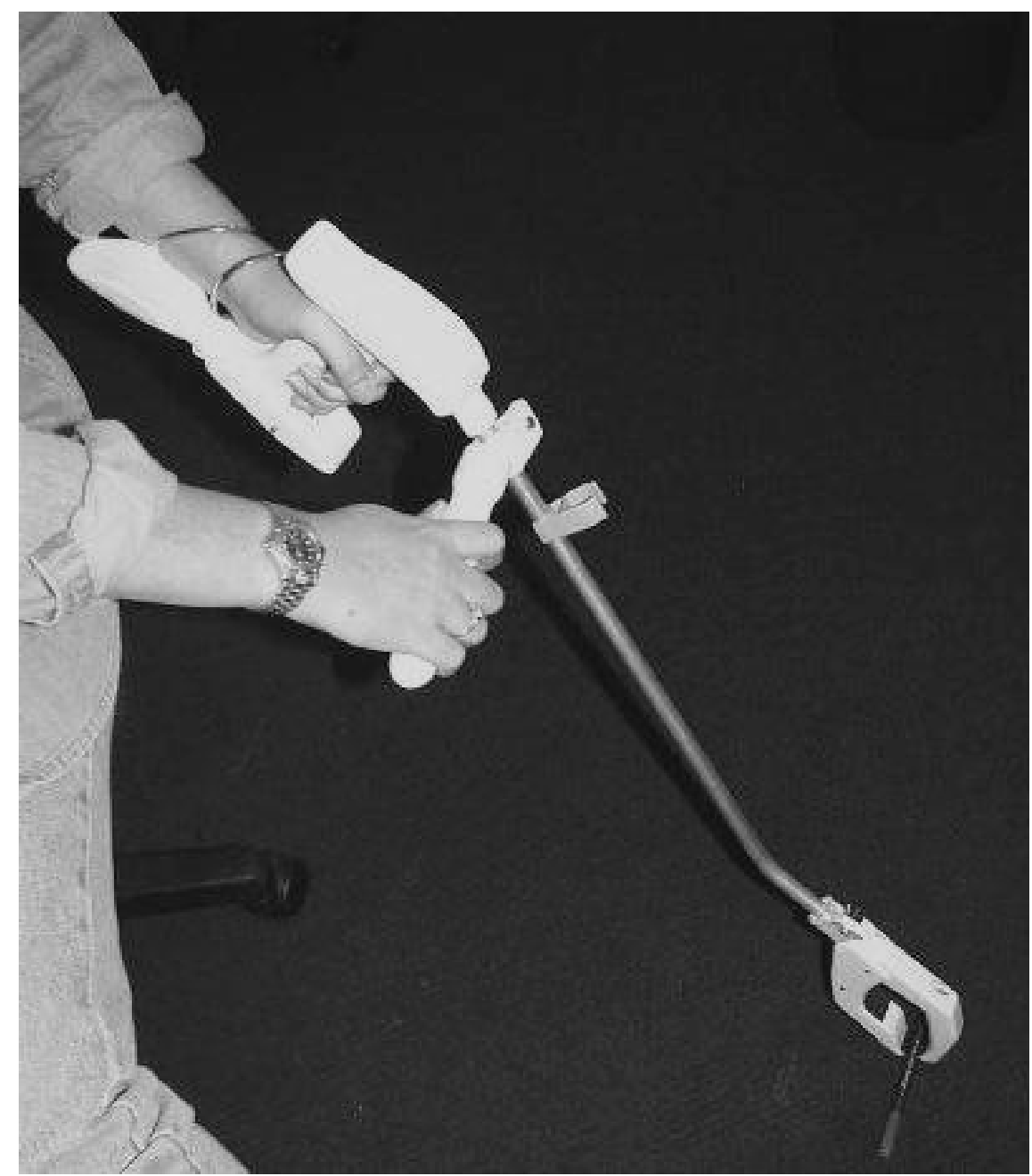

Figure 5. Shows a concept solution for an "easy-reacher" and subsequent development into a prototype (design by Roland Martino). 


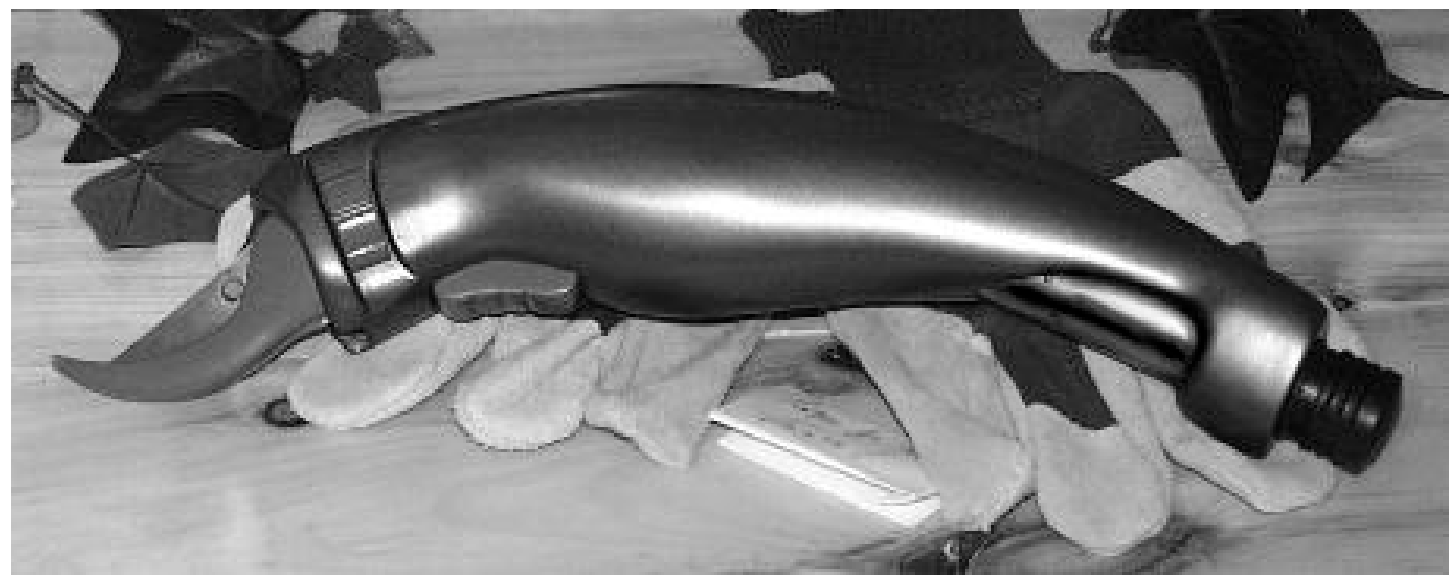

Figure 6. Shows an appearance model of a powered secateur (design by Ed Jeans).

\section{Student feedback}

In year one (1997/98) eleven of the thirty-one students completed and returned a module feedback form, which was of a University standard format. In 1998/99 twentyfive of the thirty students completed the forms. The questions are rated on a scale of five answers, from 'strongly disagree' to 'strongly agree', with a 'neutral' answer in the middle. The results show that seven of the eleven students from 1997/98 found it to be 'stimulating' and 'offering challenges that are appropriate to being a University student'. All were 'neutral' or agreed that 'the teaching helped them understand the subject'. Eight of eleven students thought the quantity of work required were well within their capabilities. A number were unhappy with the library resources available; this reflects the lack of specialist references and texts in this field. A similar result was gained when this exercise was repeated in the academic year 1998/99.

Students from both years of being taught on this module commented on the opportunity to interact with the local community, broadening their outlook on the subject of designing for elderly and disabled people. The students also suggested more reference materials be made available though the library. The author was aware that some students did not review the available literature adequately and so the weaker 
students would benefit from clear sign posting to suitable resources and to seek the assistance of briefed library staff. The expansion of the resource within the Usability-net WWW site provides further assistance to students and to practitioners working in the field.

From contacts made during this module in year one at least one student had obtained project sponsorship for another module in his final year. Reviewing design projects undertaken by students in another module it was seen that students were applying a rigorous approach to user assessments with their prototype design solutions. Students who have not been involved with the Design for Ageing and Disabilty module have requested access to the Userfit textbook when faced with user evaluations. 


\section{Conclusions}

The module has fulfilled its aim in providing an awareness of issues in the field of RT/AT research and development. The students were stimulated by the interaction with the local community and learned first hand of the difficulties of acquiring market data from consumers.

The enthusiasm of both groups of students, taking this module over the two-year period, for this topic of study was reflected in the quality of their findings. Students involved in the Design for Ageing and Disability module in 1997/98 were noted to be applying their enhanced awareness of the RT/AT field and continue to develop contacts through their work in Design Practice modules. The inter-personal skills, knowledge and practice in using ergonomics and social science based assessment techniques are clearly applicable to a broader area of industrial and product design.

In both years 1997/8 and 1998/99 of the module running, feedback from the volunteers interviewed by students was very positive and all were willing to be involved again. From 1997/98, two volunteers supplied project briefs for design practice based modules. The number of volunteers attending the student presentations in 1998/99 demonstrated this commitment. The professionals involved in community support work, such as social workers and Charity organisers were of similar opinions to the volunteers. The Department received two requests for collaborative research from contacts made during the administration of module in its first year of running. Following completion of the 1998/99 module staff of Portland College are compiling a list of design project briefs for the academic year 1999/2000.

Clearly, information about the users for whom the product is being designed is critical. The techniques highlighted in this paper enable end users to be part of product development. An objective that has long been advocated by notable members of the design community (Papanek 1971). The involvement of users provides those involved 
with a sense of empowerment. This is particularly important for people with disabilities, as demonstrated by the user feedback at the student presentations.

The need to involve users in product development should be considered an important aspect within the production of a robust product design specification (PDS). The quality of design solutions and the justification of the decision making of students who have taken part in the module described here have been notable. The documentation of a user's functional needs and social aspirations for a product enables the industrial designer to provide qualitative and quantitative evidence for their design decision making. This evidence enhances the ability of a designer to meet quality assurance requirements.

A better understanding of market research techniques and their outcomes allows an industrial designer to more thoroughly interrogate marketing colleagues about their findings. This in turn enables a designer to work more effectively within the objectives set by marketing and constraints of production within a large organisation.

\section{Issues within new product development}

The following list highlights the issues facing product developers in the field of RT/AT products:

- The market is large, but disparate, offering many niche market opportunities.

- Until recently, investment in these markets has been limited due to the perceived difficulties of marketing within this field and low disposable income of the users.

- To exploit the market as a whole a better understanding of the user groups is required to be able to identify common needs and aspirations within a single product or product range.

- Designers can use artificial impairments such as frosted or blanked glasses, clothing to restrict movement to simulate the impairments encountered by a user group. This cannot replace direct contact with the users of the new product. 
- Identification of the stakeholders within a new RT/AT product is important as the perceptions of healthcare professionals and family members towards the new product will influence a purchase as much as those of the user.

- Local charitable groups and community centres throughout the United Kingdom provide the most cost-effective way of meeting users in a neutral, accessible venue.

- Focus groups, user interviews and user product assessments, have been found to be effective in providing enough evidence for the development of a robust product design specification and reducing iterative cycles of development. Most of these techniques are documented in the USERfit textbook.

- Contacts with industry and the consumer groups involved will provide topics for student studies. The British Surgical Trades Association will provide a membership list of the majority of UK manufacturers producing RT/AT products.

- Groups such as University of the Third Age, Age Concern, Design Age, Arthritis Care, SCOPE and Government-sponsored research have highlighted a change in the lifestyle profile of those considered elderly or disabled highlighting opportunities to product developers.

- Charitable groups who support disabled and elderly people often sponsor research into the needs of their membership or group and, in some cases, new product development.

- User profiles, physical and social information may be found through a range of resources available.

- Charities are often the most accurate and up-to-date source of information and publish information that is often available free or at a subsidised low cost. A list of Government registered Charities can be obtained through most local libraries or Charities House, London.

- There are United Kingdom (UK) and European, Internet-based, databases related to this field such as: Design Age Network (DAN), European Institute for Design and Disability (EIDD) Network, and Usability-net. International networks include RESNA, the rehabilitation association of America. 
- There are numerous UK professional groups involved in this field who provide details of approaches to research and development in this field: The British Institute for Design and Disability (BIDD), Society for Research into Rehabilitation (SRR), and Institution of Physics and Engineering in Medicine and Biology (IPEMB).

- The Royal Society for the Arts, Commerce and Manufacture (RSA) have produced a teaching pack in conjunction with Design Age, Royal College of Art, London, to support student study in this area (RSA, 1995).

All of the above resources would also be of benefit to any product developer wishing to invest in AT products. Many of these resources are now available through the Internet. In the last two years, the use of the Internet as a research tool within commercial product development is becoming more evident. Most charities and even local Government organisations are producing information to be accessed through the Internet. The tools and techniques highlighted within this paper have been shown to be useful in AT product development. The techniques demonstrated by the students in this study are generic and so may be applied to any target market.

Designers have a limited experience of gender, age and race within a given society. A better understanding of the user enables more precise product design specification to be produced reducing the iterative cycle of development. The use of the techniques highlighted in this paper enable a designer to enhance their ability to empathise with the target user and provide evidence to substantiate the functional and aesthetic balance of the product solutions they present. The more a designer knows about their target market the greater likelihood of them identifying an innovative solution that provides a competitive advantage to their sponsor.

\section{Acknowledgements}

The author would like to thank the following voluntary organisations for their support in the delivery of the Design for Ageing and Disability module: Age Concern 
Liecstershire and Liecester; Active Retirement Forums in Ashby de la Zouch and Coalville, Arthritis Care Regional Office, Syston and Shepshed branches; Charnwood Community Council; Charnwood Stroke Club; Derby Royal School for the Deaf; Leicestershire Forum services to older people; Portland College, Mansfield; Loughborough Guild for the Disabled; RNIB College, Loughborough; Shepshed and District Stroke Club; The Stroke Association, East Midlands Office; and Young Arthritis Care, Loughborough. 


\section{References}

Burkitt J, Torrens GE, Kay GH, Sandbach D, Sutherland IA. (1995). The development of the Autosip: A hygienic, self-operated drinking device for people with minimal sucking ability and/or minimal arm strength., Journal of Rehabilitation Sciences, (8), 4, p115118, ISSN 09296719

Design Age, Design Age, leaflet. (1996) Royal College of Art, London

HUSAT Research Institute. (1996). USERfit: A practical handbook on user-centred design for rehabilitation and assistive technology. David Poulson, Martin Ashby, Simon Richardson (eds.), Brussels:TIDE, European Union, Maynard A. (1995). Adequate Technology, ECART 3, European conference on the advancement of Rehabilitation Technology, National Secretariat of Rehabilitation, Lisbon, Portugal, pp367-369 ISBN 9729301182

Papanek,V. (1971). Design for the real world:human ecology and social change, New York, Pantheon Books ISBN 0586081712

Royal Society for the encouragement of Arts, Manufactures and Commerce (RSA). (1995). European Design for Ageing Network: Incorporating age-related issues into design courses, RSA, London

Sandhu J, Wood T (1990). Demography and market sector analysis of people with special needs in thriteen European countries: a report on telecommunication usability issues, Special Needs Research Unit, Newcastle upon tyne polytechnic, Newcastle upon Tyne

Torrens G.E., Kay G. (1995) Design for Physical Disability: A discussion of research and development methods through to a commercial conclusion. Design Interfaces, Inaugural Conference of the European Academy of Design, University College Salford, University of Salford, Salford, U.K. Proceedings: Volume 1, Product Design, Graphic Design, ISBN 0 952566613

Torrens GE, Marshall R, Burkitt J, Kay G (1996) Using modularity to produce more competitive assistive technology products, IMC-13, (Ed) Hillery MT, Annual Conference 
of the Irish Manufacturing Committee, University of Limerick, p797-804, ISBN 1874653 380

Torrens GE, Inclusive design resources: curriculum development in the field of designing for disabled and elderly people, IDATER 96, (Ed) Smith JS, Loughborough University, 1996 p60 ISBN 1899291105

Torrens G E. (1997). Developing a robust product specification: curriculum development in the field of designing for elderly and disabled people. Poster outline, In: IDATER 97, International Conference on Design and Technology Educational Research and Curriculum, Development, John S Smith (ed.), Loughborough: Loughborough University. 1-3 September p.69.

Torrens GE, FP O'Hare. (1998). Introducing user-centred factors into a value analysis methodology during the development of a health and beauty care product. The Design Journal, (1) 2, Gower, pp27-36 ISSN 14606925

Turner A, Foster M, Johnson CE. (1996). Occupational Therapy and Physical Dysfunction, $4^{\text {th }}$ ed, Churchill and Livingstone, Edinburgh ISBN 0443051771

Young C, Sandhu J, (1995). An examination of the British Assistive Technology SME'S and their potential within the single European market, The European context for Assistive Technology, $2^{\text {nd }}$ TIDE Congress, IOS, Oxford, pp183-187 ISBN 9051992203 
